\title{
Brain-derived Neurotrophic Factor Overexpression Induces Precocious Critical Period in Mouse Visual Cortex
}

\author{
Jessica L. Hanover, ${ }^{1}$ Z. Josh Huang, ${ }^{2}$ Susumu Tonegawa, ${ }^{2,3}$ and Michael P. Stryker ${ }^{1}$ \\ ${ }^{1}$ Neuroscience Graduate Program and Department of Physiology, University of California, San Francisco, California, \\ 94143, and 2Howard Hughes Medical Institute, Center for Learning and Memory, Center for Cancer Research and \\ Department of Biology, and ${ }^{3}$ Department of Brain and Cognitive Science, Massachusetts Institute of Technology, \\ Cambridge, Massachusetts, 02139
}

\begin{abstract}
Brain-derived neurotrophic factor (BDNF) is a candidate molecule for regulating activity-dependent synaptic plasticity on the grounds of its expression pattern in developing visual cortex and that of its receptor, trkB (Castrén et al., 1992; Bozzi et al., 1995; Schoups et al., 1995; Cabelli et al., 1996), as well as the modulation of these patterns by activity (Castrén et al., 1992; Bozzi et al., 1995; Schoups et al., 1995). Infusing trkB ligands or their neutralizing agents, the trkB-IgG fusion proteins, into visual cortex alters the development and plasticity of ocular dominance columns (Cabelli et al., 1995; Riddle et al., 1995; Galuske et al., 1996; Gillespie et al., 1996; Cabelli et al., 1997). To test further the physiological role of BDNF, we studied a transgenic mouse that expresses elevated levels of BDNF in primary visual cortex (V1) postnatally (Huang et al., 1999). We
\end{abstract}

Several experiments implicate brain-derived neurotrophic factor (BDNF) in models of neuronal plasticity in vitro, including the enhancement of cortical cell dendritic morphology (McAllister et al., 1995), the enhancement of synaptic transmission (Kang and Schuman, 1995; Carmignoto et al., 1997; Rutherford et al., 1998), and the induction and maintenance of long-term potentiation in hippocampus (Korte et al., 1995; Figurov et al., 1996; Patterson et al., 1996). Results from experiments in vivo are also consistent with the idea that competition for limiting quantities of BDNF or other endogenous trkB ligands regulates synaptic plasticity during development of visual cortex by acting as the "reward" for the more active inputs that are more successful in driving the postsynaptic partners. In carnivores, providing excess trkB ligand blocks the further segregation of geniculocortical inputs into nascent ocular dominance columns and, perhaps by rewarding deprived and nondeprived inputs indiscriminately, prevents the usual loss of responsiveness of cortical neurons to the deprived eye after monocular deprivation (MD) (Cabelli et al., 1995, 1996; Galuske et al., 1996; Gillespie et al., 1996). Blocking endogenous trkB ligands also alters cortical development (Cabelli et al., 1997). In addition to its effects on excitatory neurons, BDNF is also

\footnotetext{
Received Aug. 10, 1999; revised Sept. 15, 1999; accepted Sept. 20, 1999.

This work was supported by National Institutes of Health Grants NS16033 (M.P.S.) and NS32925 (S.T.), the Damon Runyon-Walter Winchell Foundation (to Z.J.H.) and a National Eye Institute vision training grant (J.L.H.). We thank A. Antonini, N. Priebe, and M. Silver for helpful discussions.

Correspondence should be addressed to Prof. Michael P. Stryker, Department of Physiology, Room S-762, 513 Parnassus Avenue, University of California, San Francisco, CA 94143-0444. E-mail: stryker@phy.ucsf.edu.

Copyright (C) 1999 Society for Neuroscience 0270-6474/99/190001-05\$05.00/0
}

found that unlike the infusion experiments, excess BDNF expressed in mouse visual cortex did not block ocular dominance plasticity. Instead, single neurons in V1 of the BDNF transgenic mice were as susceptible to the effects of monocular deprivation (MD) as neurons in wild-type mice, but only during a precocious critical period. At a time when $\mathrm{V} 1$ in the wild-type mouse responded maximally to a $4 \mathrm{~d} \mathrm{MD}$ with a reduction in its response to deprived eye visual stimulation, the transgenic mouse V1 had already passed the peak of its precocious critical period and no longer responded maximally. This finding suggests a role for BDNF in promoting the postnatal maturation of cortical circuitry.

Key words: BDNF; visual cortex; critical period; neurotrophin; trkB; ocular dominance; plasticity; transgenic mouse known to affect inhibitory circuitry in cortical neurons (Rutherford et al., 1997).

The role of neurotrophins in the development and plasticity of rodent visual cortex is well established. Exogenous nerve growth factor (NGF) in rats can block ocular dominance plasticity or substitute for visual experience, and antibodies to NGF block normal development of cortical visual responses despite normal visual experience (Maffei et al., 1992; Berardi et al., 1994; Fagiolini and Stryker, 1996; Fagiolini et al., 1997). In most earlier experiments, exogenous BDNF has been applied pharmacologically in high concentration. In transgenic mice in which a BDNF transgene was linked to the calcium/calmodulin-dependent kinase II $\alpha(\alpha \mathrm{CaMKII})$ promoter, the levels of BDNF in cortex were only moderately elevated in the cells that normally express BDNF (Huang et al., 1999). Abnormalities in such animals could illuminate the physiological roles played by BDNF in visual cortical development.

As in wild-type animals, neocortical levels of BDNF in BDNF-

This article is published in The Journal of Neuroscience, Rapid Communications Section, which publishes brief, peerreviewed papers online, not in print. Rapid Communications are posted online approximately one month earlier than they would appear if printed. They are listed in the Table of Contents of the next open issue of JNeurosci. Cite this article as: JNeurosci, 1999, 19:RC40 (1-5). The publication date is the date of posting online at www.jneurosci.org.

http://www.jneurosci.org/cgi/content/full/3687 
overexpressing transgenic mice increased during postnatal development. BDNF mRNA expression in the cerebral cortex of the transgenic mice was accelerated by postnatal day 2 (P2), at which time the wild-type littermates showed very low levels of endogenous BDNF. By 3 weeks of age, total BDNF mRNA levels in the transgenic neocortex were significantly higher than those in wildtype animals of 5 weeks of age. At 5 weeks, BDNF mRNA levels in transgenic mouse neocortex were three times normal, and in adult transgenic mice, they were five times normal (Huang et al., 1999).

\section{MATERIALS AND METHODS}

Generation of mutant mice. Mice were generated as described previously (Huang et al., 1999). In the present study, experiments were performed on the A9 line of mice. In these animals, the expression pattern of the transgene was mainly restricted to forebrain, including the neocortex and hippocampus. Within the cortex, the expression of the transgene had the laminar pattern of the endogenous genes for BDNF or $\alpha \mathrm{CaMKII}$. In the visual cortex of both transgenic and wild-type animals, highest levels of BDNF expression were in layers II/III and V/VI; however, in transgenic animals, BDNF expression levels were substantially higher in all cortical layers. These higher levels of BDNF expression resulted from increase in the number of neurons expressing BDNF as well as an increase in the intensity of BDNF immunoreactivity in the neurons. In addition, the transgene appeared not to be expressed by neurons with inhibitory markers (Huang et al., 1999).

Monocular deprivation. Lid sutures were performed as described (Gordon and Stryker, 1996), except that anesthesia was produced using $2.5 \%$ isoflurane (Abbott, North Chicago, IL) in oxygen. Animals were checked daily to make sure that the sutured eye remained closed. If any sutures appeared loose, they were replaced under anesthesia. In the cases in which holes were apparent and the eye could have been exposed, the animals were removed from the study.

Electrophysiology. Mice were prepared blind to genotype under Nembutal $(50 \mathrm{mg} / \mathrm{kg}$; Abbott) and chlorprothixene $(0.2 \mathrm{mg}$; Sigma, St. Louis, MO) anesthesia using standard protocol (Gordon and Stryker, 1996). In each animal, single cells separated by at least $50 \mu \mathrm{m}$ were recorded from multiple penetration sites within the V1 binocular zone (BZ) contralateral to the deprived eye using extracellular tungsten microelectrodes. All recordings were contralateral to the deprived eye. Receptive fields were plotted on a tangent screen with a hand-held projection lamp or computer-generated stimuli. Only cells with receptive fields within the central $25^{\circ}$ of the visual hemifield were included in this study. The cells were assigned to an ocular dominance group according to the classification scheme of Hubel and Wiesel (1962). Cells were assigned to group 1 if they responded only to stimuli presented to the contralateral (deprived) eye and 7 if they responded only to stimuli presented to the ipsilateral (nondeprived) eye. Cells responding equally well to stimuli presented to each eye individually were assigned to group 4, and groups 2 or 3 and 5 or 6 indicated cells responding better to stimuli presented to the contralateral and ipsilateral eyes, respectively. Ocular dominance histograms such as in Figure $2 a-h$ show percent of cells as a function of ocular dominance group. The contralateral bias index $(C B I)$ was then calculated, a weighted average of the bias for one eye or the other, with the following formula: $C B I=\left[\left(n_{1}-n_{7}\right)+(2 / 3)\left(n_{2}-n_{6}\right)+(1 / 3)\left(n_{3}-\right.\right.$ $\left.\left.n_{5}\right)+N\right] / 2 N$, where $n=$ total number of cells, and $n_{\mathrm{x}}=$ number of cells with ocular dominance scores equal to $x$. Each neuron was also assigned a habituation score on a scale of 0 to 3 ; a score of 0 indicated a neuron that responded vigorously to each stimulation in a series, whereas a score of 3 indicated a neuron that habituated maximally after each presentation of the stimulus.

\section{RESULTS}

\section{Visual responsiveness}

To interpret the following experiments on cortical plasticity, it was important to ensure that the neurons in the transgenic mouse V1 were visually responsive. In transgenic (Tg) and wild-type (WT) mice at all ages studied, neurons responded to oriented bars of light moving across their respective receptive fields (Fig. $1 a, b)$. Retinotopic organization was preserved in transgenic mice and was similar to that in wild-type mice (Fig. 1c,d). Both trans-

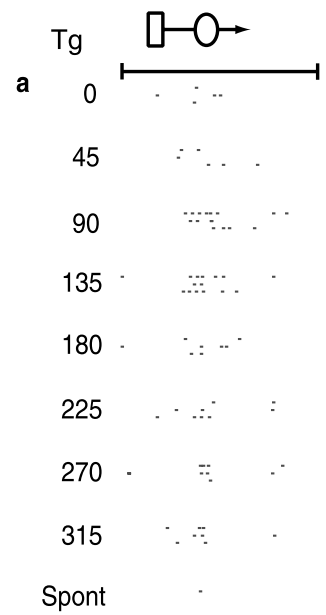

$0 . \overline{5} \mathrm{~s}$

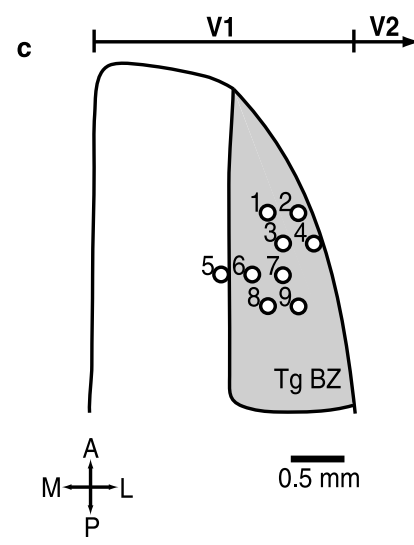

d

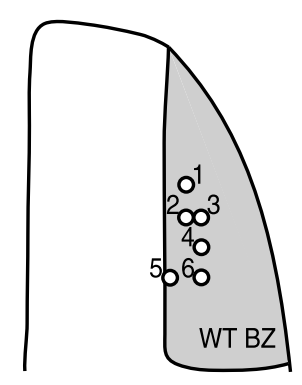

Figure 1. Visually evoked response properties of neurons in Tg and WT adult mouse V1. $a$, Raster plot of single-unit responses from a neuron in the Tg mouse V1 BZ in response to computer-generated, moving, oriented light bars $\left(0-315^{\circ}\right)$ as well as to no stimulus [spontaneous (Spont)]. Stimuli consisted of three repetitions at each of eight orientations. Spikes were continuously recorded before, during, and after the stimulus moved through the receptive field (indicated with an oval) of the neuron. $b$, Raster plot of visually evoked spikes from a neuron in the WT mouse V1 BZ. Stimuli consisted of six repetitions at each of eight orientations. $c$, Retinotopic organization in the Tg mouse V1 was preserved. As electrode penetrations moved lateral and posterior across the $\mathrm{BZ}$ in the direction of secondary visual cortex (V2), receptive field locations (ovals) moved centrally toward the vertical meridian $(V M)$ and up away from the horizontal meridian $(H M)$ in the visual field. $d$, Retinotopic organization in the WT mouse, for comparison with $c$.

genic and wild-type adult, nondeprived mice showed a contralateral bias in the $\mathrm{V} 1 \mathrm{BZ}$ as well (Tg mean $C B I=0.8$, four mice; WT mean $C B I=0.68$, four mice); the transgenic mean $C B I$ was significantly higher than the wild-type mean $C B I(p<0.05$, 

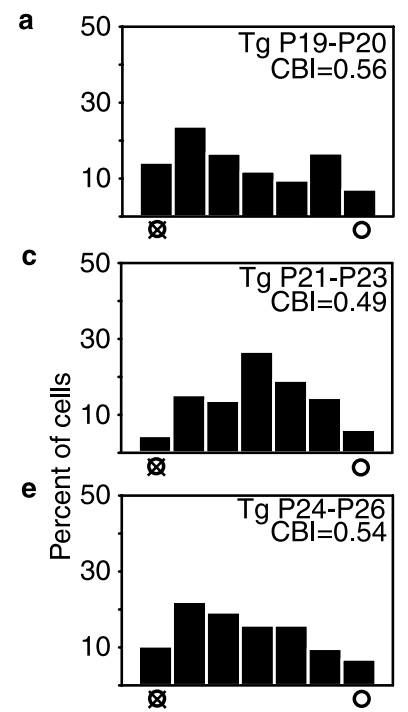

g
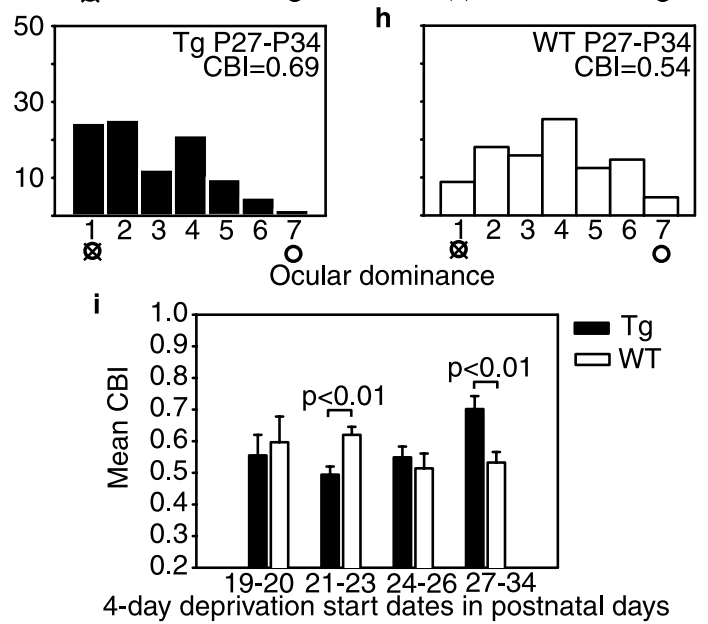

Figure 2. Ocular dominance histograms (crossed circle, deprived, contralateral eye; open circle, nondeprived, ipsilateral eye) and $C B I$ values (see Materials and Methods) for neurons recorded from Tg ( filled bars) and WT (open bars) mice in response to $4 \mathrm{~d}$ monocular deprivations at different ages. $a, b$, MD started P19-P20 (Tg, 41 cells, 2 mice; WT, 69 cells, 3 mice). $c, d$, MD started P21-P23 (Tg, 131 cells, 7 mice; WT, 131 cells, 6 mice). $e$, $f$, MD started P24-P26 (Tg, 166 cells, 9 mice; WT, 151 cells, 7 mice). $g, h$, MD started P27-P34 (Tg, 122 cells, 6 mice; WT, 272 cells, 12 mice). $i$, Mean $C B I$ values across different deprivation age groups. Note greater plasticity (lower bars) of Tg mice before P24, and lesser plasticity after P26.

Mann-Whitney $U$ test). In addition, the degree of habituation of neuronal responses to repeated stimulus presentations (see Materials and Methods) was similar in transgenic and wild-type adult mice (mean habituation scores, $\mathrm{Tg}=1.28 ; \mathrm{WT}=1.16$ ) and deprived juvenile mice $(\mathrm{Tg}=1.3 ; \mathrm{WT}=1.1)$. Therefore, defects in plasticity are not likely to be artifactually attributable to defects in visual responsiveness or overall cortical organization.

\section{Ocular dominance plasticity assessed from pooled data}

We studied developmental plasticity in the BZ of the transgenic mouse V1 by measuring the changes produced by MD in the relative responses of single neurons to input through each eye. In wild-type C57BL6 mice, a $4 \mathrm{~d}$ MD at the peak of the critical period for ocular dominance plasticity (P26-P32) produces the maximal shift in ocular dominance in the BZ (Gordon and Stryker, 1996), such that cells are now more responsive to input through the nondeprived eye. This plasticity occurs via activitydependent competition between inputs from the two eyes in V1 BZ (Gordon and Stryker, 1996). We performed $4 \mathrm{~d}$ MDs in 24 transgenic and 28 wild-type mice beginning between P19 and P34, ages before and during the normal critical period. Still blind to genotype, we assessed the ocular dominance distribution in the BZ contralateral to the deprived eye with extracellular single-unit recordings in vivo. Each isolated unit was assigned to an ocular dominance group between 1 and 7 (see Materials and Methods). The grouping of the cells was then used to calculate the $C B I$, which describes the ocular dominance distribution of the neurons in a particular cortical hemisphere (see Materials and Methods). In normal mice, the $C B I$ is $\sim 0.7$, indicating a substantial bias in favor of the contralateral eye (Gordon and Stryker, 1996). A lower $C B I$ (closer to 0 ) indicates a greater relative response to the ipsilateral eye. In our case, the contralateral eye was deprived, so a low $C B I$ indicated an ocular dominance shift in response to MD.

The overexpression of BDNF in the transgenic mouse V1 did not prevent ocular dominance plasticity. Indeed, plasticity in the BDNF transgenic mice was at least as great as normal, but it was precocious. At the earliest deprivations (P19-P20) studied, the ocular dominance distributions were similar for the two genotypes (Fig. 2a,b), and most neurons responded better to the contralateral eye despite its deprivation. After MD with start dates of P21-P23, the ocular dominance of neurons in the transgenic mouse BZ was shifted substantially (Fig. $2 c$ ), whereas the wild-type mice did not yet respond to MD to the same extent and maintained a cortex preferentially responsive to the contralateral (deprived) eye (Fig. $2 d$ ). The critical period for the transgenic mice had ended before P27, because when MD was performed starting at or after that date, neurons in V1 remained responsive to the deprived eye, and the ocular dominance distribution was entirely like that of a normal nondeprived animal (Fig. $2 \mathrm{~g}$; compare with Gordon and Stryker, 1996, their Fig. 2). In contrast, the ocular dominance distribution of wild-type animals deprived after P27 was shifted substantially away from the deprived eye

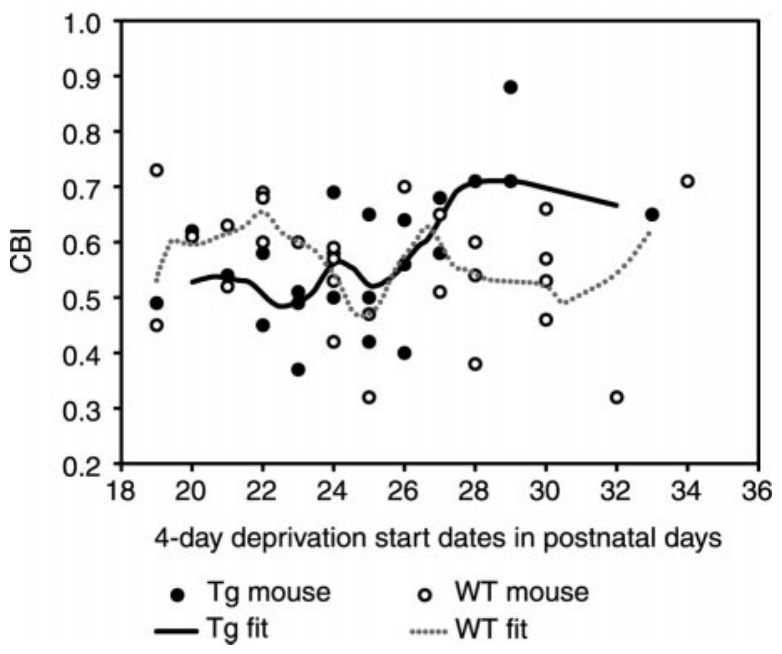

Figure 3. Scatterplots for all mice ( filled circles, Tg; open circles, WT) deprived at the different ages are overlaid with smooth curves (solid line, $\mathrm{Tg}$; dotted line, WT) generated by three-point boxcar averaging to compare the time courses of plasticity for the two genotypes. The peak (lowest $C B I$ value) for the Tg mouse $\mathrm{V} 1$ plasticity comes at $\sim \mathrm{P} 22-\mathrm{P} 23$, during which time the WT mouse V1 is nearly unresponsive to MD. The peak for the WT mouse V1 plasticity comes later, at $\sim \mathrm{P} 25$, when the Tg mice have begun to respond less to MD. 


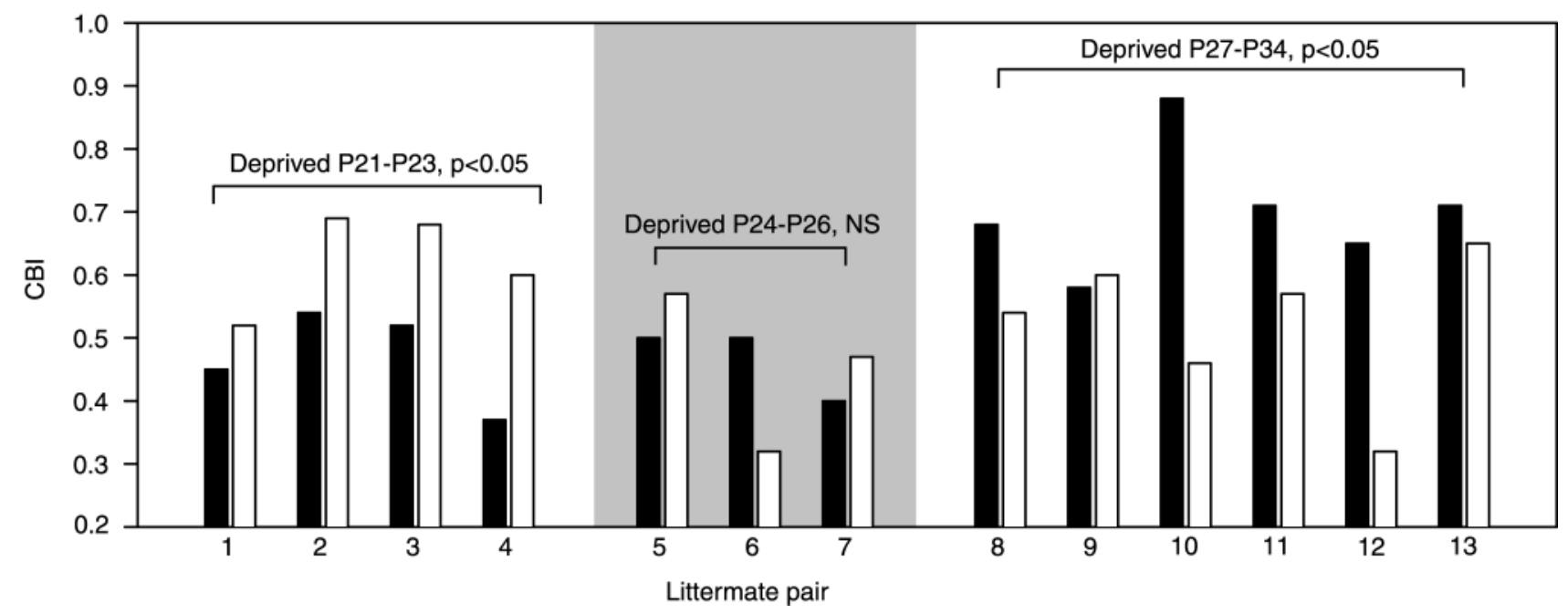

Figure 4. Paired CBI comparisons between littermates after $4 \mathrm{~d}$ MDs across different ages ( filled bars, Tg; open bars, WT). MD is more effective in Tg than in WT mice at early ages (P21-P23). The effect of MD is similar and variable at intermediate ages (shaded). MD is less effective in Tg mice than WT mice after P27.

(Fig. $2 h$ ), consistent with the peak of the normal critical period for plasticity in mouse V1 (Gordon and Stryker, 1996). Deprivations beginning at the transitional times between P24 and P26 showed an intermediate result. The transgenic neurons still shifted but less so than earlier (Fig. 2, compare $e, c$ ), and the shift in the wild-type neurons had just begun (Fig. 2, compare $f, d$ ).

\section{Analysis in individual mice}

The analysis above was based on pooling the neurons recorded in different animals. The precocious end to the critical period in the transgenic mice was also evident in the mean $C B I$ values for the different age groups, with the data from each animal equally weighted. Figure $2 i$ shows that before the normal critical period, the mean $C B I$ for the transgenic mice was shifted maximally and was significantly lower ( $p<0.01$, Mann-Whitney $U$ test $)$ than that of the wild-type mice when MD started between P21 and P23. Later, when wild-type mice were still within the peak of their critical period (MD beginning between P27 and P34), the mean $C B I$ for the transgenic mice with MD was significantly higher ( $p<0.01$, Mann-Whitney $U$ test) than that of the wild-type mice (Fig. 2i). The mean $C B I$ for the transgenic mice was also significantly higher ( $p<0.01$, Mann-Whitney $U$ test) than it had been with earlier deprivations, indicating that with MD beginning between P27 and P34, the transgenic mice did not exhibit a maximal shift. Figure 3 shows the $C B I$ for each individual deprived mouse, along with smooth curves tracing the course of visual cortical plasticity in the two genotypes. V1 in transgenic mice responded maximally to $\mathrm{MD}$ at $\sim \mathrm{P} 22$, earlier than in wild-type mice. Then the transgenic mice passed this premature peak of their critical period, and the curves for the two genotypes crossed, as V1 in wild-type mice approached its time of maximal ocular dominance shift. After P27, V1 in the transgenic mice no longer shifted, whereas in wild-type mice it continued to do so.

\section{Analysis of matched pairs}

In creating these transgenic mice, the founders were back-crossed into the C57BL6 line, introducing a possible artifact from variation in background strain expression between different litters. This was controlled for by comparing pairs of transgenic and wild-type mice within single litters, deprived within $1 \mathrm{~d}$ of each other. Figure 4 shows the results of these comparisons with littermate controls. Again, with MDs starting P21-P23, the transgenic mouse of each pair had a significantly lower $C B I$ than its wild-type littermate ( $p<0.05$, paired $t$ test), consistent with the premature plasticity of the transgenic mouse V1. Later, with MDs starting P27-P34, the transgenic mice had significantly higher CBI values than the wild-type littermates $(p<0.05$, paired $t$ test), indicating a premature close to the transgenic mouse critical period.

\section{DISCUSSION}

How can one reconcile the present results, in which overexpressed BDNF precociously enhances and prematurely ends activitydependent plasticity, with the evidence from pharmacological application of BDNF and other trkB ligands, in which activitydependent plasticity is blocked (Cabelli et al., 1995; Riddle et al., 1995; Gillespie et al., 1996)? The pharmacological experiments have been interpreted as evidence that trkB ligand is the signal by which activity promotes the growth and maintenance of connections, which are made inappropriately if the requirement for activity is short-circuited by excess trkB ligand. One possibility is that the release of the overexpressed BDNF in our transgenic mice is regulated normally, so that despite its higher level of expression, it does not short-circuit activity-dependent processes and may even enhance them. A second possibility is that BDNF is not the mediator of activity-dependent plasticity but merely promotes growth of connections until they are mature, after which it loses its effect. Both the lack of effect of exogenous trkB ligand in visual cortex after the end of the critical period (Gillespie, 1998) and the premature end of the critical period in our transgenic mice are consistent with this second possibility. The present results provide unequivocal evidence for the effect of BDNF on early maturation, and they are also consistent with the first possibility that endogenous trkB ligands may mediate activity-dependent plasticity in visual cortex.

BDNF may produce its effect on maturation by modulating inhibitory circuitry in the visual cortex. Unregulated inhibition of cortex reverses the normal direction of plasticity after MD, as assayed both physiologically and anatomically (Hata and Stryker, 
1994; Hata et al., 1999). In knock-out mice in which an isoform of the GABA-synthesizing enzyme glutamic acid decarboxylase-65 (GAD65) has been disrupted, normal ocular dominance plasticity is absent; however, it can be rescued by enhancing inhibition with diazepam during the critical period (Hensch et al., 1998). Conversely, altering visual experience can alter inhibition in cortex: MD and dark-rearing protocols, which reduce visual activity, also reduce levels of GABA and GAD (Hendry and Jones, 1986; Benevento et al., 1995), as well as BDNF mRNA levels in cortex (Castrén et al., 1992; Bozzi et al., 1995; Schoups et al., 1995).

Rutherford et al. (1997) suggested that BDNF may link activity and inhibition. In cultured cortical neurons, activity blockade reduced the number of GABAergic neurons as well as the magnitude and frequency of spontaneous IPSCs; BDNF application reversed these effects. In the visual cortex of our BDNFoverexpressing transgenic mice, the GAD65 immunoreactivity pattern matures earlier, as does long-term potentiation from the white matter to layer II/III, both phenotypes of a premature maturation of inhibitory circuitry (Huang et al., 1999). The developmentally accelerated BDNF expression in the transgenic mice may be kick starting the inhibitory system, advancing the normal period of plasticity such that it now begins and ends at earlier ages. Analysis of visual evoked potentials in these animals is also consistent with precocious maturation and an earlier critical period (Huang et al., 1999). This transgenic mouse is the first visual cortex preparation to exhibit a precocious critical period, and it should prove useful in defining the roles of BDNF and inhibition in activity-dependent plasticity.

\section{REFERENCES}

Benevento LA, Bakkum BW, Cohen RS (1995) Gamma-aminobutyric acid and somatostatin immunoreactivity in the visual cortex of normal and dark reared-rats. Brain Res 689:172-182.

Berardi N, Cellerino A, Domenici L, Fagiolini M, Pizzorusso T, Cattaneo A, Maffei L (1994) Monoclonal antibodies to nerve growth factor affect the postnatal development of the visual system. Proc Natl Acad Sci USA 91:684-688.

Bozzi Y, Pizzorusso T, Cremisi F, Rossi FM, Barsacchi G, Maffei L (1995) Monocular deprivation decreases the expression of messenger RNA for brain-derived neurotrophic factor in the rat visual cortex. Neuroscience 69:1133-1144.

Cabelli RJ, Hohn A, Shatz CJ (1995) Inhibition of ocular dominance column formation by infusion of NT-4/5 or BDNF. Science 267:1662-1666.

Cabelli RJ, Allendoerfer KL, Radeke MJ, Welcher AA, Feinstein SC, Shatz CJ (1996) Changing patterns of expression and subcellular localization of trkB in the developing visual system. $\mathrm{J}$ Neurosci 16:7965-7980.

Cabelli RJ, Shelton DL, Segal RA, Shatz CJ (1997) Blockade of endogenous ligands of trkB inhibits formation of ocular dominance columns. Neuron 19:63-76.

Carmignoto G, Pizzorusso T, Tia S, Vicini S (1997) Brain-derived neurotrophic factor and nerve growth factor potentiate excitatory synaptic transmission in the rat visual cortex. J Physiol (Lond) 498:153-164.

Castrén E, Zafra F, Thoenen H, Lindholm D (1992) Light regulates expression of brain-derived neurotrophic factor mRNA in rat visual cortex. Proc Natl Acad Sci USA 89:9444-9448.

Fagiolini M, Stryker MP (1996) Delayed onset of NGF effects on ocular dominance plasticity in mice. Soc Neurosci Abstr 22:1729.
Fagiolini M, Pizzorusso T, Porciatti V, Cenni M, Maffei L (1997) Transplant of Schwann cells allows normal development of the visual cortex of dark-reared rats. Eur J Neurosci 9:122-112.

Figurov A, Pozzo-Miller LD, Olafsson P, Wang T, Lu B (1996) Regulation of synaptic responses to high-frequency stimulation and LTP by neurotrophins in the hippocampus. Nature 381:706-709.

Galuske RAW, Kim D, Castrén E, Thoenen H, Singer W (1996) Brainderived neurotrophic factor reverses experience-dependent synaptic modifications in kitten visual cortex. Eur J Neurosci 8:1554-1559.

Gillespie DC (1998) Neurotrophins in development and plasticity of cat primary visual cortex. Ph.D. Thesis, University Microfilms, 9839475:1142.

Gillespie DC, Crair MC, Stryker MP (1996) NT-4/5 infusion alters plasticity and responses of cat primary visual cortex during the critical period. Soc Neurosci Abstr 22:276.

Gordon JA, Stryker MP (1996) Experience-dependent plasticity of binocular responses in the primary visual cortex of the mouse. J Neurosci 16:3274-3286.

Hata Y, Stryker MP (1994) Control of thalamocortical afferent rearrangement by postsynaptic activity in developing visual cortex. Science 265:1732-1735.

Hata Y, Tsumoto T, Stryker MP (1999) Selective pruning of more active afferents when cat visual cortex is pharmacologically inhibited. Neuron 22:375-381.

Hendry SHC, Jones EG (1986) Reduction in number of immunostained GABAergic neurones in deprived-eye dominance columns of monkey area 17. Nature 320:750-753.

Hensch TK, Fagiolini M, Mataga N, Stryker MP, Baekkeskov S, Kash SF (1998) Local GABA circuit control of experience-dependent plasticity in developing visual cortex. Science 282:1504-1508.

Huang ZJ, Kirkwood A, Pizzorusso T, Porciatti V, Morales B, Bear MF, Maffei L, Tonegawa S (1999) BDNF regulates the maturation of inhibition and the critical period of plasticity in mouse visual cortex. Cell 98:739-755.

Hubel DH, Wiesel TN (1962) Receptive fields, binocular interaction and functional architecture in the cat's visual cortex. J Physiol (Lond) 160:126-154.

Kang H, Schuman EM (1995) Long-lasting neurotrophin-induced enhancement of synaptic transmission in the adult hippocampus. Science 267:1658-1662.

Korte M, Carroll P, Wolf E, Brem G, Thoenen H, Bonhoeffer T (1995) Hippocampal long-term potentiation is impaired in mice lacking brainderived neurotrophic factor. Proc Natl Acad Sci USA 92:8856-8860.

Maffei L, Berardi N, Domenici L, Parisi V, Pizzorusso T (1992) Nerve growth factor (NGF) prevents the shift in ocular dominance distribution of visual cortical neurons in monocularly deprived rats. J Neurosci 12:4651-4662.

McAllister AK, Lo DC, Katz LC (1995) Neurotrophins regulate dendritic growth in developing visual cortex. Neuron 15:791-803.

Patterson SL, Abel T, Deuel TAS, Martin KC, Rose JC, Kandel ER (1996) Recombinant BDNF rescues deficits in basal synaptic transmission and hippocampal LTP in BDNF knockout mice. Neuron 16:1137-1145.

Riddle DR, Lo DC, Katz LC (1995) NT-4-mediated rescue of lateral geniculate neurons from effects of monocular deprivation. Nature 378:189-191.

Rutherford LC, DeWan A, Lauer HM, Turrigiano GG (1997) Brainderived neurotrophic factor mediates the activity-dependent regulation of inhibition in neocortical cultures. J Neurosci 17:4527-4535.

Rutherford LC, Nelson SB, Turrigiano GG (1998) BDNF has opposite effects on the quantal amplitude of pyramidal neuron and interneuron excitatory synapses. Neuron 21:521-530.

Schoups AA, Elliott RC, Friedman WJ, Black IB (1995) NGF and BDNF are differentially modulated by visual experience in the developing geniculocortical pathway. Dev Brain Res 86:326-334. 